\title{
COMENTARIOS AL PRIMER PLENO CASATORIO CIVIL
}

\author{
Manuel Miranda Canales*
}

\begin{abstract}
Resumen
Se presenta una comentario panorámico sobre la realización del Primer Pleno Casatorio realizado en la historia del Poder Judicial. Se destaca las posiciones discrepantes de las Salas Supremas Especializadas en lo Civil, así como la posición final de la Sala Plena de la Corte Suprema respecto a la validez de la transacción extrajudicial en un proceso judicial.

De igual forma se hace mención a la trascendencia de este Pleno Casatorio y su importancia para la predictibilidad de las resoluciones judiciales y seguridad jurídica del país.
\end{abstract}

Palabras clave: Pleno Casatorio, predictibilidad, transacción.

\begin{abstract}
This is a panoramic review of the First Repealing Plenary session realised in the history of the Judicial Power of Peru. Stands out the discrepant positions of the Civil Supreme Rooms, as well as the final position of the Total Room of the Supreme Court, refered to the validity of the extrajudicial transaction in a judicial process.

Likewise it is mentioned the importance of this Repealing Plenary session and its importance for the predictability of the judicial veredicts and legal security of the country.
\end{abstract}

Keywords: Repealing Plenary session, predictability, transaction.

* Vocal Provisional de la Corte Suprema de Justicia de la República del Perú. Profesor de la Universidad Nacional Mayor de San Marcos y Universidad San Martín de Porres. 
En primer lugar, debemos decir que el señor Presidente de la Corte Suprema de Justicia y del Poder Judicial, el doctor Francisco Artemio Távara Córdova, ha tenido el acierto y la decisión - hasta heroica - de realizar el Primer Pleno Casatorio desde la publicación del Código Procesal Civil, que introdujo la institución de la casación en el proceso civil.

El 18 de diciembre de 2007, por primera vez, se realizó un Pleno Casatorio, en el que intervinieron los Señores Vocales Titulares de la Corte Suprema y emitieron una decisión en un tema en el que las dos Salas Civiles de la Corte Suprema - Permanente y Transitoria - tenían discrepancias sobre si una transacción extrajudicial tenía valor o no en un proceso judicial.

¿Qué había sucedido? Se produjo un derrame de mercurio en Cajamarca el cual ocasionó daños en la salud de varias personas del lugar, razón por la cual la empresa Minera Yanacocha, transó con algunos afectados, plasmándose el acuerdo en escritura pública. Pasó el tiempo y las personas afectadas interpusieron una demanda de indemnización por daños y perjuicios, ante ello, la Minera Yanacocha, interpuso la excepción de conclusión del proceso por transacción extrajudicial.

La Sala Civil Permanente, consideró que esa transacción tenía valor, debido a que se había celebrado con observancia de los elementos esenciales para la validez del acto jurídico (artículo $140^{\circ}$ del Código Civil), además, se precisó que se había transigido sobre bienes disponibles, objeto de la indemnización.

Por su parte, la Sala Civil Transitoria, consideró que la transacción extrajudicial, en términos generales, no tenía validez, en razón de que se había transigido sobre un bien indisponible (la salud de las personas) y; además, porque la transacción no se había dado dentro del proceso. La Sala Civil Permanente, sobre este último punto, decía que tenía validez cualquier transacción, así se diera fuera del proceso.

Ante este escenario, se decidió realizar el Primer Pleno Casatorio al amparo del artículo $400^{\circ}$ del Código Procesal Civil, que establece que debe haber una Sala Plena Casatoria para que se establezca la doctrina jurisprudencial y, en ese sentido, se realizó este Pleno en la Sala de Juramentos del Palacio de Justicia, con el informe oral de los abogados de Minera Yanacocha, aunque con la lamentable ausencia de los abogados de los afectados.

Los Señores Vocales de la Corte Suprema debatieron ampliamente y han establecido que la transacción extrajudicial tiene valor en el proceso judicial. 
Lógicamente se emitieron criterios discrepantes muy valiosos y respetables que se insertaron en la resolución casatoria.

Además quisiera precisar, que cuando se discuten temas académicos, lo que está en juego es lo siguiente: ¿Una transacción extrajudicial puede servir de sustento para deducir la excepción de transacción? Este es un tema muy discutido, como cualquier aspecto del derecho, porque nuestro mismo sistema jurídico es abierto, debido a que pertenece al sistema romano-germánico; no es como el common law. Por ello, el magistrado para aplicar la ley al hecho concreto y convertir la justicia abstracta -que se encuentra en la ley-, en justicia concreta en la sentencia, tiene que interpretar y utilizar su criterio jurisdiccional; y como el derecho, casi siempre permite por lo menos dos interpretaciones, es necesaria la realización permanente de los plenos casatorios.

Reitero, ha habido comentarios del caso Yanacocha, como si se tratase más de tal o cual que interviene en un proceso y no del caso mismo. Sobre nosotros los magistrados, específicamente en este caso los Vocales Titulares de La Corte Suprema, que son los que participan en el pleno casatorio, esta situación no tiene absolutamente ninguna influencia. La Corte Suprema cuenta con magistrados de basta calidad profesional y moral, todos son doctores, magísteres en derecho, docentes universitarios; hay autores de libros: gente con experiencia; hay idoneidad, probidad, imparcialidad, independencia, honestidad. Por eso, aquellos comentarios no los tomamos en cuenta. Vale por eso la aclaración.

Se debe notar, en primer lugar, que uno de los grandes aciertos de la actual gestión de la Presidencia de la Corte Suprema es haber realizado por primera vez un Pleno Casatorio.

En segundo lugar, esto contribuye a la seguridad jurídica del país, porque a veces se dice que la Corte Suprema emite una resolución vinculante, y ello no es así. La Corte Suprema, emite una resolución que constituye un precedente, pero no de obligatorio cumplimiento, por lo menos en lo civil. Para que sea de obligatorio cumplimiento tiene que ser pronunciada por una Sala Plena Casatoria, dando nacimiento a lo que se denomina la doctrina jurisprudencial. Por eso a veces, los magistrados, lo decimos con todo respeto, vemos algunos recursos de casación que no tienen sustento, por falta de una mayor difusión de esta nueva institución. Debería intensificarse su difusión en las universidades y realizarse seminarios, conferencias, diplomados y cursos de capacitación sobre el recurso de casación en los distintos colegidos de abogados y otras instituciones. A veces encontramos que el abogado dice: 
“Señor, se ha aplicado indebidamente, o se ha interpretado erróneamente o se ha inaplicado la doctrina jurisprudencial", ¿Cuál doctrina jurisprudencial? no había doctrina jurisprudencial hasta el 18 de diciembre de 2007 sobre el tema de la validez de la transacción extrajudicial en un proceso judicial. Sobre eso, ahora ya hay.

Ahora, en cualquier caso, cuando haya un proceso en el que hubo una transacción extrajudicial semejante a este, seguramente un abogado honesto y correcto hará notar la transacción y el proceso se podrá concluir rápidamente. Esa validez ya la ha establecido la Sala Plena Casatoria.

Mientras que en otros casos, todavía no hay plenos casatorios, sobre tantos otros temas debatibles. Los órganos jurisdiccionales, en la mayoría de las veces, dan respuestas distintas. En las universidades, esto no se ha podido distinguir bien. Lo universitarios se preguntan por qué un juez en un caso dice A, y otro juez, en un caso similar, da una respuesta distinta, incluso contraria. Hubo una interpretación distinta, no ha habido nada incorrecto ni irregular, sino que ese magistrado, para aplicar la ley y resolver aquel punto que se sometió a su decisión jurisdiccional, ha interpretado de una manera la ley, y otro magistrado, la interpreta de manera distinta y así sube a la Sala Superior, y de la misma manera a la Corte Suprema, donde existen dos Salas Civiles, en las que se mantiene la dicotomía. En ese caso, debe convocarse a pleno casatorio, y lo que ahí se decida, eso es lo obligatorio y vinculante. De manera que, para nuestro sistema, se ha dado un avance que debe tenerse en cuenta y que debiera continuarse, porque por primera vez se ha creado doctrina jurisprudencial, en los términos prescritos en el artículo $400^{\circ}$ del Código Procesal Civil.

La incidencia que tendrá este Primer Pleno Casatorio, respecto a las transacciones extrajudiciales dentro de un proceso, es su eficacia de dar seguridad jurídica. De ahora en adelante, se sabrá que esa decisión se dio en un pleno casatorio, teniendo un efecto vinculante y todos tendremos que cumplirlo. No habría otra alternativa. Con los plenos casatorios, algún abogado podrá saber que en determinado asunto sobre un tema - que ya haya sido visto en un pleno casatorio - ya ha perdido o ganado el caso sin siquiera haber comenzado el proceso, justamente por la decisión emitida en pleno casatorio. En el caso de la jurisprudencia emitida por La Corte Suprema, ésta no es vinculante. Adviértase además, que sólo puede cambiarse los acuerdos de un pleno casatorio en otro pleno casatorio convocado con arreglo a la normatividad adjetiva. 
Respecto a la influencia del pleno casatorio en el caso de los intereses difusos, en mi concepto es un poco forzado que esta situación sea tomada en cuenta para el tema de los intereses difusos. Puede que haya una referencia. Particularmente, me parece que aún no va a tener una incidencia. Por el contrario, en el futuro, si hay dos posiciones contrarias o contradictorias, también podría haber un pleno casatorio.

Desde mi experiencia en la magistratura, quiero felicitar, por la realización de este Primer Pleno Casatorio al señor Presidente del Poder Judicial y a los Vocales Titulares de la Corte Suprema, que tienen interés y voluntad para continuar con los plenos casatorios, para debatir los temas de mayor trascendencia. Entendiéndose éstos no por su valor económico o de otra índole, sino por los temas que deben debatirse: cómo debe ser una correcta interpretación de una norma de derecho material, cómo debe aplicarse debidamente, por qué se inaplicó una norma de derecho material, cómo debe respetarse el debido proceso y las formas esenciales para la validez de los actos procesales y crear la doctrina jurisprudencial. Eso es necesario. Invoco pues, a los Colegios de Abogados, a las Facultades de Derecho y a todas las instituciones vinculadas con el sistema jurídico, a que investiguen más sobre dichos plenos, y difundir más el tema, con la intervención de magistrados, profesores universitarios, abogados, estudiantes y la comunidad en general, a fin de superar las notorias deficiencias en que se incurre en la formulación de los recursos de casación, lo cual se aprecia en las varias oportunidades en las que la Corte Suprema, hablando estadísticamente, declara en su gran mayoría improcedentes los recursos de casación, en razón de las deficiencias técnico-jurídicas en la formulación de éstos. Y no es porque hay situaciones de irregularidad.

El recurso de casación es uno extraordinario: tiene requisitos de fondo y de forma rigurosos, y a veces el abogado no los conoce, y esto no depende sólo de él, depende además de las Universidades, los Colegios de Abogados y el Poder Judicial. 